\title{
A CONSTRUÇÃO DO \\ HUMOR PELA POLIFONIA \\ E INTERTEXTUALIDADE \\ NO VÍDEO \\ “É PAU, É PEDRA"
}

\section{LA CONSTRUCCIÓN DEL HUMOR A TRAVÉS DE LA POLIFONÍA Y INTERTEXTUALIDAD EN EL VIDEO “É PAU, É PEDRA”}
THE CONSTRUCTION OF HUMOR THROUGH POLYPHONY AND INTERTEXTUALITY IN THE VIDEO “É PAU, É PEDRA"

Fernanda Trombini Rahmen Cassim*

Professora da Rede Particular

Bruno Franceschini**

Universidade Federal de Goiás - Regional Catalão

RESUMO: Este artigo, pautado nos estudos de Bakhtin (2002) e de Ducrot (1987), tem como objetivo analisar a construção do humor por meio da polifonia e da intertextualidade no vídeo "É pau, é pedra", do canal "Porta dos Fundos". Por meio da análise do jogo argumentativo que se dá entre os personagens, compreensível no universo do humor, analisa-se a escala argumentativa dada pelos interlocutores, a qual traz a polifonia do texto: vozes que ora representam o desejo de virilidade, ora representam outros desejos sociais. O entrecruzamento de vozes ocorre em uma construção de exclusão: são questões impossíveis de serem conciliadas, pressupondo um diálogo que prevê preferências. O tamanho do pênis, nesse caso, representa a obsessão pelo papel viril. A intertextualidade inclui e exclui os interlocutores, fazendo referências intertextuais específicas. Assim como a polifonia, a intertextualidade é também geradora de humor no texto.

PALAVRAS-CHAVE: Polifonia. Humor. Escalas Argumentativas.

\footnotetext{
* Graduada em Letras e em Psicologia pela Universidade Estadual de Maringá, possui Mestrado e Doutorado em Estudos Linguísticos também pela Universidade Estadual de Maringá. Atua como Professora do Ensino Básico na rede privada e como Psicóloga Clínica. E-mail: fer_trc_@hotmail.com. 
RESUMEN: Este artículo, basado en los estudios de Bakhtin (2002) y Ducrot (1987), tiene como objetivo analizar la construcción del humor a través de la polifonía y la intertextualidad en el video "É pau, é pedra", del canal "Porta dos Fundos". A través del análisis del juego argumentativo que tiene lugar entre los personajes, comprensible en el universo del humor, se analiza la escala argumentativa dada por los interlocutores, que trae la polifonía del texto: voces que a veces representan el deseo de virilidad, a veces representan a otros deseos sociales. La intersección de las voces ocurre en una construcción de exclusión: estas son preguntas imposibles de conciliar, suponiendo un diálogo que prevea las preferencias. El tamaño del pene, en este caso, representa la obsesión con el papel viril. La intertextualidad incluye y excluye interlocutores, haciendo referencias intertextuales específicas. Al igual que la polifonía, la intertextualidad también genera humor en el texto.

PALABRAS CLAVE: Polifonía. Humor Escalas argumentativas.

ABSTRACT: In this paper, based on the studies of Bakhtin (2002) and Ducrot (1987), we aim to analyze the construction of humor through polyphony and intertextuality in the video "É pau, é pedra", produced by "Porta dos Fundos" channel. Through the analysis of the argumentative game that occurs between the characters, comprehensible in the universe of humor, we analyze the argumentative scale given by the interlocutors, which brings the polyphony of the text: voices that represent the desire for virility, and sometimes represent other social desires. The intercrossing of voices occurs in a construction of exclusion: these are issues that cannot be reconciled, assuming a dialogue that foresees preferences. The size of the penis, in this case, represents the obsession with the manly role. Intertextuality includes and excludes interlocutors by making specific intertextual references. Like polyphony, intertextuality also produces humor in the text.

KEYWORDS: Polyphony. Humour. Argumentative scales.

\section{INTRODUÇÃO}

Este texto tem por objetivo discutir o humor em perspectiva polifônica, observando o funcionamento heterogêneo do discurso, assim como a argumentação que se apresenta na língua em um vídeo retirado de uma plataforma de vídeo digital. Para tanto, consideramos a língua e a linguagem como práticas dialógicas em que observamos, na primeira, a materialização de questões discursivas e, na segunda, o modo pelo qual essas mesmas questões também se materializam em outros suportes. Assim, vislumbramos o vídeo em estudo como um texto, um suporte para que seja possível a apreensão do nível discursivo inerente a este, tendo em vista o fato de que, por meio do dialogismo e dos mecanismos polifônicos, o sujeito que enuncia nessa materialidade se constitui como sujeito de discurso, caracterizando, desse modo, conforme Authier-Revuz (1982, 1990), as formas de heterogeneidade: a constitutiva - em que há, no enunciador, a ilusão de ser a origem do discurso - e a mostrada - na qual a voz do outro é explicitada por meio de mecanismos linguístico-discursivos que marcam essa inserção do discurso do outro.

Para este artigo, por meio da análise de como as questões argumentativas estão manifestadas na língua, pretendemos discorrer acerca das formas da heterogeneidade e de intertextualidade presentes na materialidade audiovisual "É pau, é pedra", que critica, de forma humorística, o universo masculino e sua relação com seu genital. Para além dessa leitura, discutimos também como esses elementos, em perspectiva discursiva, constituem o texto e são produtores de sentido, uma vez que o efeito de sentido se dá no sujeito e a produção desses sentidos necessita do conhecimento do leitor-interlocutor na apreensão do intertexto. Com vistas a cumprirmos com os objetivos estabelecidos, utilizamos os trabalhos de Authier-Revuz (1982, 1990) sobre heterogeneidade enunciativa, de Ducrot (1987) sobre as estratégias argumentativas do dizer e a polifonia, e dos estudos do Círculo de Bakhtin (1992, 1997) para a dimensão dialógica do discurso.

\section{A DIMENSÃO DIALÓGICA E HETEROGÊNEA DO DISCURSO}

Por comungarmos da perspectiva dialógica do discurso, segundo o que é desenvolvido pelos estudos bakhtinianos, constatamos que todo discurso traz em suas palavras as palavras do outro. Nesse movimento, as questões discursivas, as quais englobam aspectos sociais, históricos e ideológicos, também são observadas, uma vez que o dialogismo pressupõe a interação entre sujeitos, um dos aspectos fundadores da linguagem. Neste artigo, observamos os processos discursivos postos em circulação na materialidade 
audiovisual em estudo, almejando a descrição da construção do humor pelos mecanismos polifônicos, pela intertextualidade e pelo modo como as estratégias argumentativas estão organizadas na língua.

Para Bakhtin (1997), dadas as condições de produção, cada enunciado é único e resultado do estabelecimento de uma relação dialógica entre sujeitos, produto de uma teia de enunciados anteriores. Na análise de um enunciado em perspectiva discursiva, precisamos considerar elementos exteriores à língua, ou seja, as condições sociais e históricas que permitiram a efetivação desse discurso porque "[...] o todo do enunciado se constitui como tal graças a elementos extralinguísticos (dialógicos), e este todo está vinculado a outros enunciados" (BAKHTIN, 1997, p. 335).

O discurso como centro é, na teoria bakhtiniana, o ponto de partida de toda investigação sobre o homem, é um estatuto pleno de objeto linguístico-discursivo, social e histórico. É, ainda, um produto da criação ideológica de uma enunciação, compreendendo o contexto histórico, social, cultural etc. No caso deste estudo, tomamos a materialidade audiovisual como um texto e analisamos seus aspectos linguístico-discursivos que colocam em circulação enunciados verbais e imagéticos em circulação, ou seja, problematizamos a argumentação realizada como não sendo feita de forma intencional e questionamos as condições históricas para que os enunciados fossem produzidos de modo a investigarmos os efeitos de sentido de humor produzidos pelo vídeo em estudo.

Para Barros (1999, p. 24), "O texto não existe fora da sociedade, só existe nela e para ela e não pode ser reduzido à sua materialidade linguística ou dissolvido nos estados psíquicos daqueles que o produzem ou o interpretam”. Ou seja, não se deve reduzi-lo ao empirismo objetivo ou subjetivo. Ele deve ser analisado pelo caráter ideológico dos discursos. Nesses discursos, falam vozes diversas que mostram a compreensão que cada classe ou segmento de classe tem do mundo em um dado momento histórico.

O vídeo em estudo coloca em discurso um tema que existe socialmente, e julgamos ser necessária a análise de tal texto, uma vez que essa produção humorística ironiza as questões inerentes ao universo masculino heteronormativo, como o falocentrismo discursivizado no caso em análise: o tamanho do pênis. Assim, procuramos analisar as questões argumentativas presentes e como, por meio da argumentação, ocorre a produção de sentidos no batimento entre língua e história.

Consoante ao Círculo de Bakhtin, Barros (1999) demonstra que todo texto é dialógico, ou seja, define-se pelo diálogo entre interlocutores e pelo diálogo com outros textos (da situação, da enunciação), construindo a significação e produzindo sentidos. Para Bakhtin (2002), o enfoque dialógico da linguagem constrói o sujeito em um processo de interação no qual o indivíduo se vê e se reconhece através do outro, em um universo povoado por uma multiplicidade de sujeitos interdependentes e isônomos.

Pelo seu caráter dialógico, o discurso é sempre responsivo, trazendo em si um conjunto de vozes e de ideologias outras que o constituem. Sendo assim, o dialogismo seria o princípio da constituição da linguagem e de todo discurso, partindo do princípio de que nenhuma palavra é própria do falante, mas traz em si a perspectiva da voz do outro, no enunciado em estudo: como os sujeitos presentes no vídeo são constituídos pelo discurso machista.

No âmbito da produção de sentidos, a compreensão textual também é dialógica e, como afirma Barros (1999), compreender é opor à palavra do interlocutor outra palavra: a compreensão é ativa e deve conter o germe de uma resposta. Por fim, para Bakhtin (1992, p. 90), "[...] a língua apresenta-se como uma corrente evolutiva ininterrupta". Concebemos a língua como um fato social e, ao considerarmos a interação com o outro, compreendemos a dimensão responsiva do discurso no funcionamento de um elo comunicativo em situações interacionais dadas.

Muitas vezes, esse dialogismo deixa-se entrever. Nos textos em que isso ocorre - chamados polifônicos -, são percebidas muitas vozes, opondo-se a textos monofônicos, os quais escondem os diálogos que os constituem sob a aparência de uma única voz (BARROS, 1994). Bakhtin (2002) entende que a polifonia se caracteriza pela posição do enunciador enquanto regente do grande coro de vozes que participam do processo dialógico. Esse regente, por sua vez, é dotado de um ativismo especial, rege vozes que ele cria ou recria, mas deixa que se manifestem com autonomia e que revelem no homem um outro "eu para si" infinito e inacabável. 
Embora dialogismo e polifonia sejam termos algumas vezes utilizados como sinônimos nos escritos de Bakhtin, Barros (1994) deixa clara a oposição entre textos monofônicos e polifônicos. Mesmo sendo o dialogismo a condição fundamental da linguagem e do discurso, há textos predominantemente polifônicos ou monofônicos, dependendo das estratégias discursivas acionadas. Nos textos polifônicos, os diálogos entre discursos deixam-se ver ou entrever; nos textos monofônicos, eles se ocultam sob a aparência de um discurso único.

No texto em análise, analisamos a ocorrência do funcionamento polifônico e dialógico do discurso no que compete aos temas que são trazidos para a interação entre os sujeitos, tais como questões de saúde, sociais, econômicas e políticas, as quais têm como pano de fundo o desejo do enunciador por um pênis dois centímetros maior, desejo esse que analisamos como um princípio de um discurso machista centrado em um aspecto falocêntrico, que produz sentidos, de humor pela ironia, em sujeitos que compreendem a relação dialógica e polifônica estabelecida na materialidade audiovisual.

Dentre as características dialógicas da linguagem, Ducrot (1987) aprofundou os estudos de Bakhtin e formulou A teoria polifônica da enunciação. Como postula Ducrot (1987, p. 193), a polifonia é caracterizada quando um locutor L apresenta em seu enunciado dois enunciadores distintos, no entanto esse locutor L assume a responsabilidade pelo enunciado e os enunciadores pela posição adotada.

De acordo com Fávero (1999), a noção de dialogismo remete à explicitada por Kristeva ao sugerir que Bakhtin, ao falar de duas vozes coexistindo em um texto, teria apresentado a ideia de intertextualidade. Esse aspecto da intertextualidade, abordado por Bakhtin, prevê o diálogo entre os muitos textos da cultura. Nesse caso, há o primado do intertextual sobre o textual: a intertextualidade não é mais uma dimensão derivada, mas a dimensão primeira de que o texto deriva.

Salientamos, assim, que o discurso de humor solicita do leitor uma compreensão dos domínios linguístico e discursivo, ou seja, é requerido do interlocutor que recupere as pistas na materialidade deixadas pelo enunciador, as quais possibilitarão a apreensão da argumentatividade no texto, sendo que, por meio do funcionamento polifônico, é possível "[...] a indicação da operação argumentativa que está por trás da incorporação da voz do outro no discurso em pauta” (BENITES, 2002, p. 90), podendo essa operação produzir um efeito de sentido de humor. Como explica Brait (1996, p. 58), "[...] é possível observar alguns mecanismos de construção textual cujo conjunto pode produzir efeitos irônicos e humorísticos. [...] E é precisamente através desse mecanismo fundamental da linguagem que a ironia se concretiza”.

Porém, de acordo com Barros (1999), deve-se observar que a intertextualidade na obra de Bakhtin é, antes de tudo, a intertextualidade 'interna' das vozes que falam e polemizam no texto, nele reproduzindo o diálogo com outros textos. Para Lopes (1999), a intertextualidade nasce da percepção da disjunção existente entre as vozes do texto e, para Fiorin (1999), o conceito de intertextualidade concerne ao processo de produção do sentido.

A intertextualidade é, então, o processo de incorporação de um texto a outro, seja para reproduzir o sentido incorporado, seja para transformá-lo. A partir disso, entendemos que a intertextualidade é um processo constitutivo do texto, derivado da polifonia, em que as vozes presentes no texto transformam o seu sentido por referência a um intertexto. Conforme Brait (1996, p. 66),

De maneira bastante genérica, pode-se dizer que a transposição se dá na medida em que o enunciado, independentemente de sua extensão, será observado através das marcas que aí estão assinaladas, produtos de um processo que envolve as relaçoes dialógicas necessariamente existentes entre a instância de produção e a instância de recepção, o que significa considerar no mínimo dois agentes responsáveis pela significação: enunciador e enunciatário. Se o enunciatário não se der conta das articulações entre os segmentos aí envolvidos, a significação irônica não terá lugar.

Assim, no estudo aqui realizado, procuramos descrever os modos pelos quais o locutor L se enuncia acerca de temas alheios à condição sócio-histórica de onde se encontrava: o mictório. Pela descrição da condição de produção do enunciado em análise, temos um primeiro delineamento acerca do humor, quando dois homens conversam no banheiro sobre o tamanho de seus pênis. Ao longo do diálogo travado, observamos como o locutor L estrutura o seu discurso e recorre à ironia e a mecanismos intertextuais para 
fazer funcionar a argumentação na língua de modo a defender o seu ponto de vista, que é o de aumentar dois centímetros em seu genital. Já no domínio dos efeitos de sentido, analisamos que o vídeo produz humor ao recorrer a elementos externos, intertextuais, como já mencionado, e esse movimento de produção de sentido se dá na relação com o outro, corroborando, desse modo, o funcionamento dialógico do discurso.

\subsection{O HUMOR}

É difícil afirmar, hoje, que há uma teoria complexa sobre o humor. Possenti (1998) acredita que o humor não deve ser uma preocupação exclusiva da Linguística e que sequer há uma Linguística do humor. Porém, para Possenti (2001), o que se sabe sobre o discurso humorístico é que este perpassa questões contextuais, de conteúdo, ideológicas e culturais. É necessário ressaltar que, segundo o autor, o humor provém da combinação de elementos linguísticos e discursivos, do exterior à língua, ou seja, o que é dito, a forma do discurso e os elementos que estão fora do que é linguístico - dentre os quais podemos citar a história, a cultura e a sociedade - são igualmente determinantes para a forma de manifestação do discurso.

O humor é utilizado de formas variadas, podendo ser encontrado em gêneros que não sejam exclusivamente humorísticos, como na ironia de um artigo de opinião, por exemplo. Para Possenti (2000), o fato é que o discurso humorístico consegue dizer o que não pode ou não deve ser dito, provavelmente porque não há um juízo de valor sobre quem conta ou quem ouve o discurso humorístico. É como se o enunciador se despisse do caráter culposo de uma afirmação racista em uma piada, por exemplo; ou se ele se distanciasse do que pode ou não pode ser possível no mundo real.

Ao refletir sobre a função do texto e do leitor no processo de leitura e interpretação, Possenti (1998) explica que os textos humorísticos supõem uma espécie de controle de sua interpretação, isto é, se não acontecer a compreensão necessária do efeito humorístico, eles perderão sua função principal: serem percebidos como textos humorísticos.

O papel social do humor, portanto, pode variar, e também sua estrutura argumentativa, podendo levar o destinatário a aderir a diferentes perspectivas ideológicas. Como elucida Ducrot (1987, p. 193), “[...] de maneira análoga, o locutor, responsável pelo enunciado, dá existência, através deste, a enunciadores de quem ele organiza os pontos de vista e as atitudes." Desse modo, é por essa inserção do dizer do outro que o enunciador põe em circulação os discursos que produzirão efeitos de sentido distintos a depender do interlocutor.

Quanto aos temas, Possenti (1998) afirma que o texto humorístico não traz nada de novo, pois todo dito é um já-dito, ou seja, o humor retoma discursos existentes, assim como o fenômeno polifônico, quando retoma e introduz o dizer do outro, bem como o dialógico, ao estar em um elo com outros discursos. Esses discursos podem variar desde o âmbito crítico a crenças sociais carregadas de preconceito. Assim, o texto humorístico pode servir para contestar estruturas sociais, ressaltando seus absurdos, ou, por outro lado, reforçar comportamentos ridicularizantes. Têm-se como exemplo as piadas que constantemente ridicularizam os homossexuais, os nordestinos, as mulheres e os negros.

\subsection{A ARGUMENTAÇÃO NA CONSTRUÇÃO DO TEXTO}

A teoria polifônica auxilia na descrição do sentido dos enunciados. Ao analisar o entrecruzamento de vozes em um texto, é possível que se constitua uma imagem do enunciador do texto e de seu(s) destinatário(s). Para Ducrot (1987), esse fato gera uma identificação - ao menos parcialmente - dos enunciadores e destinatários, que advém da compreensão do sentido do enunciado. As significações do texto obrigam a reconstituir os debates que se encontram dentro do discurso. Já para Bakhtin (1992, p. 140),

[...] a todo instante se encontra nas conversas 'uma citação' ou 'uma referência' àquilo que disse uma determinada pessoa, ao que 'se diz' ou àquilo que 'todos dizem', às palavras de um interlocutor, às nossas próprias palavras anteriormente ditas, a um jornal, a um decreto, a um documento, a um livro. 
Nesse ínterim, Ducrot (1987) demonstra que a argumentação é o fator essencial para a apreensão do sentido do enunciado. Para ele, a linguagem coloca a subjetividade do eu na interpretação, ou seja, o locutor expressa seu ponto de vista no discurso, por isso não é mais possível aceitar o caráter objetivo da linguagem. Assim sendo, a argumentação é uma subjetividade inevitável.

Essa argumentação é organizada por marcadores linguísticos ou operadores argumentativos (DUCROT, 1987). Para o autor em menção, a argumentação é inerente à língua e certas palavras da língua possuem força argumentativa, produzida, particularmente, por esses operadores. Os operadores são responsáveis pelo encadeamento dos argumentos em uma escala argumentativa (DUCROT, 1987), direcionando o argumento para essa ou aquela conclusão.

Segundo Ducrot (1987), as categorias da argumentação se dão por classe argumentativa e escala argumentativa. A primeira é constituída de um conjunto de enunciados que podem igualmente servir de argumento para uma mesma conclusão. Assim, todos os argumentos têm o mesmo "peso" para levar o destinatário a alguma conclusão. Já a segunda é uma categoria usada para classificar os enunciados de acordo com sua força no discurso, com o auxílio dos operadores argumentativos, que assinalam o argumento mais forte de uma escalada orientada no sentido de uma determinada conclusão. Neste trabalho, buscaremos analisar a escala argumentativa utilizada no texto e como ela pode atuar produzindo humor.

\section{DO HUMOR EM PERSPECTIVA POLIFÔNICA E AS RELAÇÕES INTERTEXTUAIS}

Os vídeos postados no canal "Porta dos Fundos" contam com um título e uma descrição, e analisamos, neste texto, o material "É pau, é pedra”, cuja significação é uma referência intertextual à música “Águas de Março”, composta por Tom Jobim. Essa clássica canção da MPB é uma referência descritiva de uma série de elementos metafóricos, os quais levam a uma gama de significados possíveis. Porém, no contexto do vídeo em análise, chegamos à metaforização do termo "pau”, que, em nossa cultura, refere-se ao pênis. O termo "pedra" pode adquirir uma aproximação semântica relacionada à dificuldade que o personagem tem com seu pênis. O vídeo possui a seguinte descrição:

Homens são casados com o próprio pau. Na saúde e na doença, na riqueza e na pobreza, é ele que sempre estará lá pro que der e vier. O problema é que toda relação precisa de um desabafo, de uma DR. E isso normalmente acontece na hora da boa e velha mijada. Exceto quando você é divorciada como a Lea T.

A intertextualidade com a música de Tom Jobim constrói uma paródia na comparação de uma obra clássica da MPB com a relação entre o homem e seu pênis. Ao realizar essa intertextualidade, o enunciador espera que o destinatário reconheça o intertexto, criando a incompatibilidade humorística em universos textuais - entre a culta e clássica MPB e uma discussão banal sobre pênis. A respeito da intertextualidade e da incompatibilidade humorística, Authier-Revuz (1990, p. 31) explicita esse funcionamento em que o enunciador insere o discurso do outro e marca, assim, "[...] um exterior explicitamente especificado ou dado a especificar".

A descrição inicia com uma saudação informal entre os sujeitos discursivizados no vídeo, tendo como sequência uma pergunta categórica sobre a relação do homem com o pênis, já demonstrando o universo em que essa esquete humorística se insere:

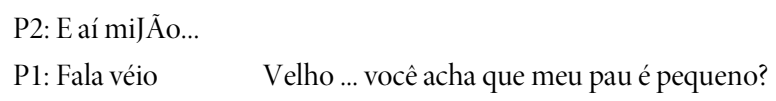

A partir deste enunciado, observamos como os locutores já dão início às estratégias argumentativas para colocar em discurso o estereótipo de homem viril sobre o qual o vídeo irá falar, que prioriza seu membro sexual com a seriedade de uma relação matrimonial - conforme vemos na intertextualidade com os dizeres típicos de uma cerimônia de casamento, no segundo período. É a partir desse universo que o leitor compreenderá o humor do vídeo, um universo onde o que impera é o estereótipo do homem alfa, do homem detentor da virilidade e do poder social e sexual. O pênis seria o representante maior dessa virilidade, da possibilidade sexual insaciável, poligâmica e reprodutora. 
Essa identidade masculina se constrói diante de modelos previamente existentes, evidenciados pelo que Butler (1990) chama de biopolíticas regulatórias vistas em um sistema que produz sexismos. Para a autora, a educação dada ao homem, desde a infância, prevê que ele aja de forma que deva se afastar a todos os significantes que o levem ao universo feminino, especialmente no que tange a estar sempre com outros homens, fazendo com que a socialização masculina se dê de forma diferente da feminina. Isso se observa no discurso em análise, onde há uma interação masculina em que o único lugar que a mulher ocupa é o de objeto de desejo. Tudo isso constrói um modelo fechado de masculinidade para nossa sociedade, o qual define discursos específicos e relações de gênero já esperadas. O pênis, que pode ser tomado, nesse discurso, como representante maior desse desempenho de gênero e masculinidade a partir de uma perspectiva falocêntrica, gera um simbolismo que recupera a construção dessa masculinidade viril.

Segundo Bakhtin (2006), os simbolismos que se dão pela linguagem constituem-se como objetos ideológicos, refletindo uma realidade social e material. A palavra é a representação desses objetos, de modo a materializar práticas ideológicas. Nesse sentido, $o$ falo se torna um simbolismo formador de material para análise, interpretação e compreensão da linguagem em suas mais variadas formas, fornecendo a possibilidade de pesquisa sobre a construção da identidade cultural - nesse caso, da identidade do homem viril.

Ao comparar a relação entre o homem e seu pênis com o casamento, há a afirmação de que "toda relação precisa de um desabafo, de uma D.R.", popularmente conhecida como "discussão de relacionamento", em que casais tratam de problemas decorrentes da relação. Essa comparação feita pelo autor faz com que imaginemos previamente que esse personagem tem problemas com seu pênis e precisa expô-los para resolvê-los - e é exatamente o que ocorre no vídeo.

Ao final da descrição, afirma-se que essa discussão ocorre em um momento específico ("na hora da boa e velha mijada”) e que a exceção está quando o homem é divorciado - novamente a referência ao casamento - do pênis, metáfora que remete à cirurgia de troca de sexo feita por transexuais. Para exemplificar, utiliza-se a figura pública de Lea T., uma estilista e modelo transexual brasileira.

O mais importante dessa descrição são as referências intertextuais com o casamento, a fim de deixar em foco a importância da relação entre o homem e seu pênis para, com isso, reforçar e antecipar o universo no qual a piada do vídeo deverá ser compreendida.

Nesse funcionamento discursivo da polifonia, observamos o jogo do humor colocado em circulação segundo dois aspectos: a conclusibilidade do enunciado e o caráter bivocal do discurso de humor, que apresenta um significante recoberto por dois significados (BRAIT, 1996). Sobre a conclusibilidade e a produção de sentido de humor, Bakhtin (2003, p. 275) escreve:

A conclusibilidade do enunciado é uma espécie de aspecto interno da alternância dos sujeitos do discurso, essa alternância pode ocorrer precisamente porque o falante disse (ou escreveu) tudo o que quis dizer em dado momento ou sob dadas condições. Quando ouvimos ou vemos, percebemos nitidamente o fim do enunciado, como se ouvíssemos o "dixi” conclusivo do falante. Essa conclusibilidade é específica e determinada por categorias específicas.

O vídeo se inicia com a imagem de um homem, interpretado por Victor Leal, urinando em um banheiro, remetendo a um estabelecimento informal, quando o segundo personagem, interpretado por Antonio Tabet, chega com um copo de cerveja na mão para urinar ao lado do já conhecido colega, sendo que esta configuração cenográfica é analisada, por nós, em consonância com o pensamento de Bakhtin (2011), no todo arquitetônico do enunciado.

A esse respeito, a disposição do cenário organiza o tempo-espaço e fornece as condições necessárias para a produção dos enunciados e, por consequência, do sentido. Dito de outro modo, o diálogo em análise no vídeo se dá tendo em vista o local onde se passa - o mictório - e essa interação entre os sujeitos não se daria se estes estivessem em um box reservado. Portanto, na composição do enunciado, o todo arquitetônico se dá pela articulação do contexto da obra enquanto um objeto estético, bem como pela integração do verbo com a imagem, que significam e produzem sentidos acerca da virilidade masculina retratada no vídeo em uma perspectiva humorística. 
O banheiro, o copo de cerveja, os cumprimentos "E aí, mijão", "Fala, véio", caracterizam não só o lugar físico onde os personagens se encontram, mas o lugar de onde falam, o estereótipo do universo masculino em nossa cultura. A configuração do humor já se dá nesse momento, na apresentação desse estereótipo, agindo como condição de possibilidade para a produção desse discurso, conforme explica Possenti (1998, p. 25), pois há uma questão contraditória neste espaço masculino: o banheiro e o modo como a conversa se desenrola ao longo do vídeo, porque, "[...] nesse sentido, as piadas são uma espécie de sintoma, já que, tipicamente, são relativas a domínios discursivos 'quentes"'. Ou seja, trata-se de um assunto espinhoso em que o chiste, o humor, a piada, adquirem um mecanismo de proteção para os locutores. Diz-se "sintoma" porque, na impossibilidade, na vergonha ou no temor de falar sobre o assunto (o tamanho do pênis), criam-se mecanismos substitutos. Assim, criar a piada é sintomático no sentido de que ela substitui uma ação impossível de ser realizada de outra forma.

Também devemos considerar o universo heteronormativo em que se dá o diálogo. Os argumentos trazidos e a polifonia do texto remontam ao diálogo entre dois homens heterossexuais avaliando o tamanho de suas genitálias. Isso se comprova pelas referências que serão analisadas ao longo deste artigo, como "suruba com as Panicats" ou "figurinista gostosa", aludindo ao desejo heterossexual em questão. Butler (1990), sobre a heterossexualidade, demonstra que a noção de matriz heterossexual se configura pela formação discursiva dominante cuja formação ideológica do sujeito observa a heterossexualidade normativa, a partir de um continuum entre sexo, gênero e desejo, em que o sexo anatômico seria normalizante da orientação sexual e do desejo.

Assim, o falocentrismo do diálogo aqui analisado remonta a essa normatização, uma vez que o discurso se volta para o desejo por mulheres enquanto os locutores falam do pênis e, doravante, faremos referência a eles como Locutor/Personagem 1 (P1) e Locutor/Personagem 2 (P2), respectivamente.

Cria-se, também, uma tensão nesse universo heteronormativo, quando há uma situação tão íntima entre dois homens heterossexuais falando sobre seus membros. O aparente desconforto, o forçoso "não olhar" para o pênis do outro também são ações geradoras do humor, pois revelam uma incapacidade constrangedora de lidar com o diálogo.

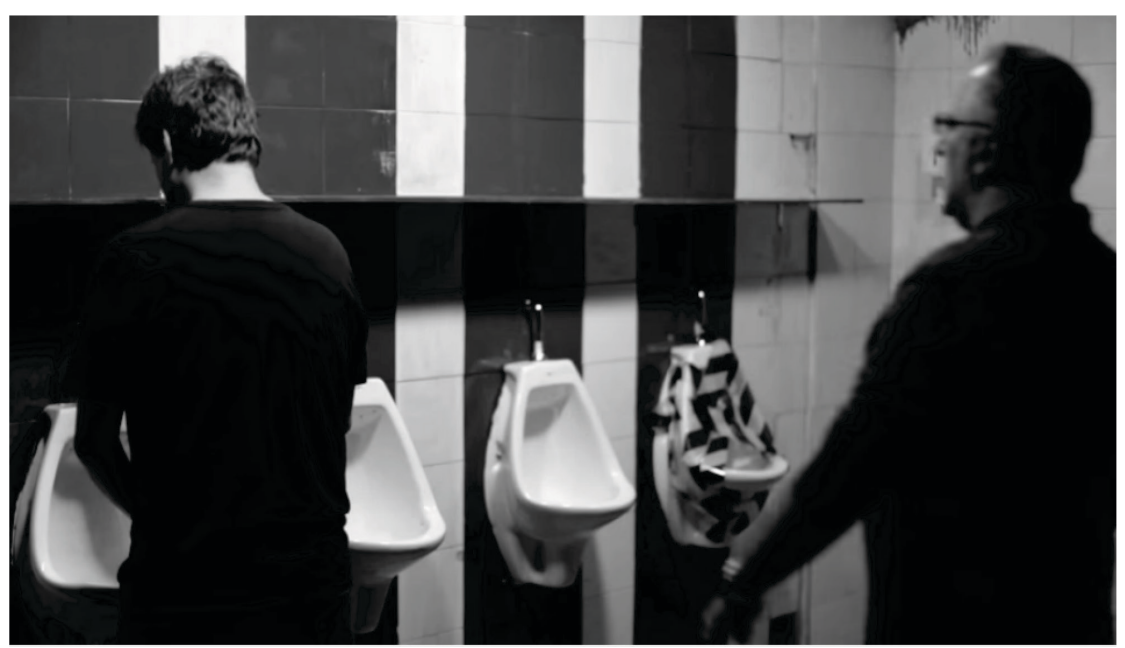

Imagem 1: Local, cumprimentos, personagens

Fonte: "É pau, é pedra" (2013) 


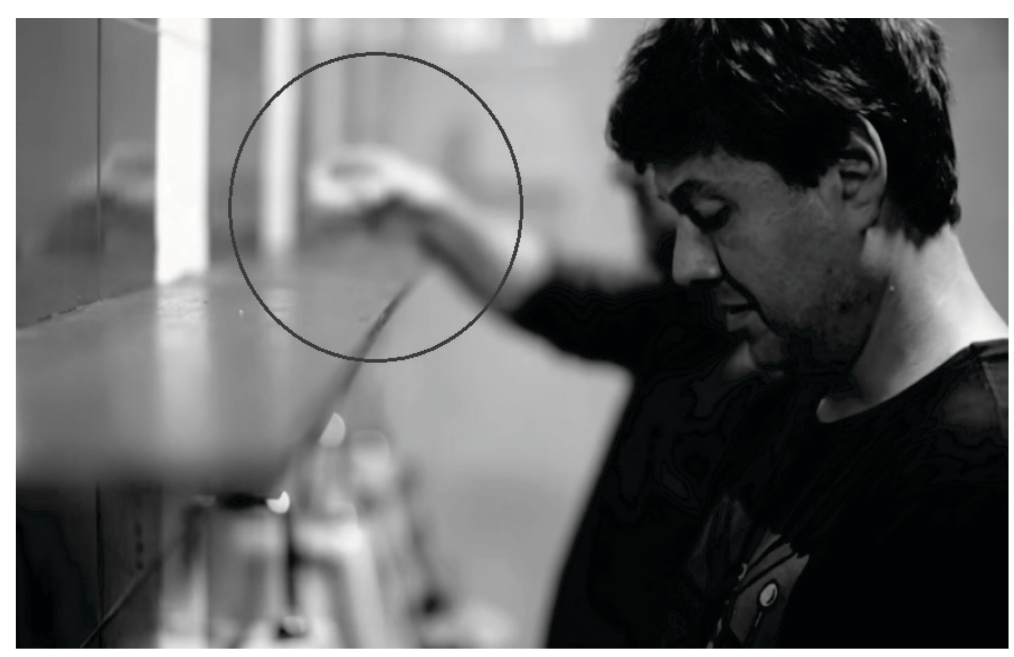

Imagem 2: A bebida como marcadora do estereótipo masculino

Fonte: "É pau, é pedra" (2013)

Vejamos a seguir a transcrição do diálogo inicial do vídeo ${ }^{1}$ :

P2: E aí miJÃo...

P1: Fala véio Velho .. você acha que meu pau é pequeno?

P2: Ah, peQUEno Nãoé grande não.

P1: Mas não é preocuPAN::te...

P2: Eu já vi menores...

P1: Você acha que tem alguma providê::ncia, alguma coisa assim que eu possa fazer pa resolver esse negócio aqui? P2: Não não.. Pau grande ou cê tem ou cê num tem né

P1: É né..

P2: Ah..

P1: E você?

$\mathrm{P} 2$ : Eu?

P1: É.

P2: Eu ganho mais na largura mesmo né

P1: Ahm:: na bitola

P2: Ta vendo a chapelota aqui vai descendo tipo um tacape

P1: Ahm::: ta.

P2: É no Peso, entendeu?

P1: É mais gordinho. Parece um champignon só que maior assim né.

P2: É, isso. De repente o teu duro aí dá uma alegria, dá não?

P1: Éh.......

P2: Não né?

P1: Éh n... éh num sei

P2:.. Sei

P1: Eu to te perguntando sabe por quê? Porque ó eu vou fazer .. quarENta agora mês que vem

$\mathrm{P} 2: \mathrm{Hm}$..

P1 Acho que não cresce mais não será que cresce?

P2: .... não .... quarenta não vai crescer mais ..

P1: Não né

P2: Não De repente dar uma aparada né

${ }^{1}$ A transcrição foi feita alfabeticamente seguindo-se um padrão baseado nas normas do projeto NURC (PRETI, 1993), com algumas adaptações. 
P1: Ahm:: pode crer, abaixar aqui assim o mato né

P2: Pé direito aumenta um pouquinho:: parte branca ali ó

P1: Ó já da um alô né

P2: Na marquise ali

P1: Verdade

P2 Já reclamaram?

P1: Não, reclamar não. Nunca.. reclamação assim formal reclaMA::R .. não

P2: Também nenhuma mulher reclama né

P1: Não né

P2: Chegar assim ó na tua CARA .. falar essa tripa de mico seca veia aí... essa língua de gato .. esse Cheetos molhado pra cima de mim .. não vai falar isso pro cara..

P1: Não é nem elegante né

P2: É.. não..

P1: Te falar o que eu queria .. Queria mais dois centímetros de PAU

P2: É né...

P1: É::

P2: É, mas quem não queria, né?..

P1: É?

P2: É Dois centímetros de pau ou cem mil reais?

P1: Dois centímetros de pau

P2: Na lata, assim?

P1: Na LA.. ih::

P2: Dois centímetros de pau ou uma cobertura no Leblon?

P1 Dois centímetros de pau

P2: Dois centímetros de pau ou a cura do câncer?

P1: Aí: $\quad$ se bem que célula tronco ta vindo com tudo aí, né.

O diálogo transcrito não só mostra a intimidade entre os personagens, mas também um assunto em comum: o tamanho do pênis. Podemos caracterizar o Locutor 2 como o enunciador da autoestima viril, pois em momento algum ele coloca em questionamento o tamanho do seu pênis, pelo contrário, valoriza-o: Tá vendo a chapelota aqui vai descendo tipo um tacape. Já o Locutor 1 assume a posição do enunciador inseguro, que busca no amigo respostas a respeito do tamanho do seu pênis.

Essa questão interfere diretamente em nossa análise, pois se trata das vozes que se entrecruzam e evocam outras vozes para construir a argumentação textual. Ao analisarmos esse funcionamento, observamos que há o agenciamento para a estruturação da argumentação pretendida e para a produção do efeito de humor. Como aponta Maingueneau (1983, p. 76-78), "[...] há polifonia quando é possível distinguir em uma enunciação dois tipos de personagens, os enunciadores e os locutores. O locutor, então, é compreendido como o ser responsável pelo seu enunciado".

A seguir, temos a transcrição do texto para nossa principal análise:

P2: É... Dois centímetros de pau ou cem mil reais?

P1: Dois centímetros de pau

P2: Na lata, assim?

P1: Na LA.. ih::

P2: Dois centímetros de pau ou uma cobertura no Leblon?

P1: Dois centímetros de pau

P2: Dois centímetros de pau ou a cura do câncer?

P1: Aí: $\quad$ se bem que célula tronco ta vindo com tudo aí, né.

[CRÉDITOS] 
P2: Dois centímetros de pau ou uma suruba com as Panicats?

P1: Dois centímetros de pau

P2: Dois centímetros de pau ou passe livre?

P1: Dois centímetros de pau

P2: Dois centímetros de pau ou um programa de viagem com o Luquita da Galera?

P1: Dois centímetros de pau

P2: Dois centímetros de pau ou aquela figurinista gostosa da Porta dos Fundos?

P1: Dois centímetros de pau

P2: Dois centímetros de pau ou cinco centímetros de pau?

P1: Dois centímetros de pau

Observamos, então, que o Locutor 1 exprime seu desejo de ter um pênis maior e, diante disso, o Locutor 2 busca, por meio do resgate de outras vozes, testar o amigo, observar quão grande é o seu desejo. Primeiramente, ele questiona ao amigo se ele prefere "2 centímetros de pau ou cem mil reais”. Assim, ele contrapõe o desejo expresso pelo Locutor 1 à questão financeira. Para trazer essa nova voz, ele utiliza o operador argumentativo "ou”, o qual se caracteriza, segundo Koch (2008), por ser um operador que serve para indicar conclusões alternativas, induzir argumentos alternativos, levando a conclusões opostas ou diferentes. Por isso, para trazer uma nova voz ao texto, o locutor utiliza-se desse operador argumentativo, deixando clara a oposição entre os argumentos e fazendo com que o Locutor 1 escolha apenas um deles.

Vendo que o Locutor 1 persiste no desejo inicial (2 centímetros de pau), o Locutor 2 busca outra voz para o contrapor, ainda mais valorizada em nossa cultura, o status, ofertando-lhe bens materiais (uma cobertura no Leblon). O telespectador deve, nesse momento, recorrer ao seu conhecimento de mundo para perceber que esse novo argumento é ainda maior ou melhor que o primeiro, tendo em vista que uma cobertura no Leblon, bairro nobre do Rio de Janeiro, custa em torno de trinta milhões de reais. Essa retomada intertextual é indispensável na instauração de argumentos. É através dela que percebemos a insistência do Locutor 2 em fazer o Locutor 1 desistir de seu desejo inicial.

Em terceira instância, o Locutor 2 invoca um novo frame para contestar seu amigo: a cura do câncer, a qual representa o altruísmo frente a uma doença grave que mata muitas pessoas mundialmente e que ainda não tem cura. Nesse sentido, entendemos que esse novo frame seria ainda mais relevante do que a questão financeira e de status, já negadas pelo Locutor 2 . Ao trazer a voz da benevolência, o Locutor 2 espera que o Locutor 1 abdique de seu desejo por ter 2 centímetros a mais de pênis.

Obviamente, o cenário da discussão é absurdo, assim como as escolhas sistemáticas do Locutor 1. Ela só é possível se levarmos em conta que estamos em um lugar específico do humor, do absurdo, do comportamento machista sexualizado em demasia. Só é possível entender esse diálogo ao admitirmos o estereótipo dado pelo humor. A esse respeito, Brait (1996) explica que o jogo enunciativo entre os locutores é um fenômeno polifônico por jogar com uma lógica de elementos contraditórios e, para Ducrot (1987, p. 197), "Um enunciador irônico consiste sempre em fazer dizer, por alguém diferente do locutor, coisas evidentemente absurdas, a fazer, pois ouvir uma voz que não é a do locutor e que sustenta o insustentável”.

Vejamos, agora, a escala argumentativa dada pelo Locutor 2, a fim de contestar a escolha do Locutor 1 por um pênis maior:

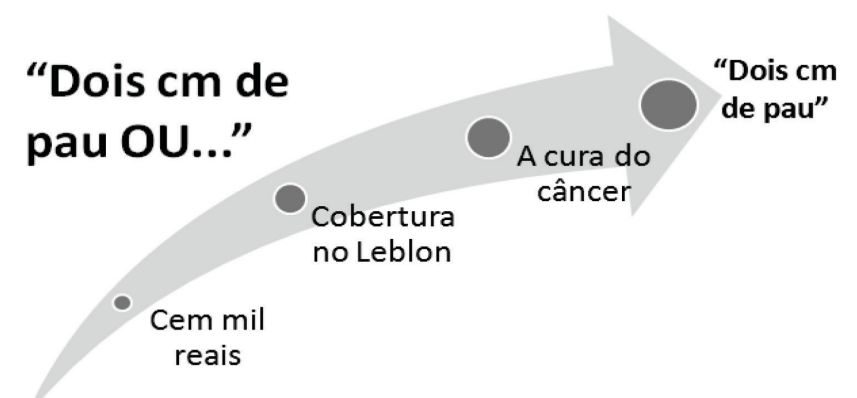

Diagrama 1: Primeira escala argumentativa dada pelo Locutor 2 
Na escala argumentativa dada, o argumento primeiro, que traz à tona o dinheiro, tem menor valor. Por conseguinte, o status e a possibilidade de ter ainda mais dinheiro do que na proposta anterior também é superada pelo desejo de um pênis maior. Por fim, $o$ altruísmo e o bem universal também são colocados com menor importância frente ao desejo de ter mais " 2 centímetros de pau", ainda que com ressalvas. O Locutor 1 hesita em fazer sua escolha no caso da cura para o câncer, comprovando a posição desse argumento na escala argumentativa, à frente do dinheiro e do status. Colocar o tamanho do pênis acima dos outros argumentos apresentados é o que gera o humor pelo exagero, pelo absurdo. Um fato absurdo que só caberia no contexto em questão. Sendo absurdo, o humor gera a crítica ao apego ao pênis, ao louvor excessivo pela virilidade masculina. Satiriza-se a forma como os homens que se encaixam nessa caricatura dão mais valor ao próprio órgão sexual do que ao dinheiro e à cura do câncer.

Nos créditos do vídeo, justamente pelo humor gerado pelo embate de vozes ao final, o autor continua com o mesmo processo, repetindo a forma de argumentação. A repetição insistente também é uma característica do humor, provoca riso pela reiteração absurda do Locutor 2. É importante destacar que, nos créditos, utiliza-se mais a intertextualidade.

Como explica Bakhtin (2011, p. 297),

Cada enunciado é repleto de ecos e ressonâncias de outros enunciados com os quais está ligado pela identidade da esfera de comunicação discursiva. Cada enunciado deve ser visto antes de tudo como uma resposta aos enunciados precedentes de um determinado campo (aqui concebemos a palavra "resposta" no sentido mais amplo): ela os rejeita, confirma, completa, baseia-se neles, subentende-os como conhecidos, de certo modo os leva em conta. Porque o enunciado ocupa uma posição definida em uma dada esfera de comunicação, em uma dada questão, em um dado assunto etc.

A partir disso, observamos a construção dos enunciados como respostas sequenciais - ou ecos, de fato, como afirma Bakhtin (2011) - em que há uma avaliação para posterior rejeição. O “dado assunto”, nesse caso, poderia ser o universo viril e a sexualidade ou heteronormatividade posta em questão.

As escalas argumentativas dadas pela polifonia e pela intertextualidade continuam sendo exploradas pelo Locutor 2. Em seguida, ele opõe o desejo do Locutor 1 a "uma suruba com as Panicats". Essa nova voz representa o sexo, um argumento por meio do qual o Locutor 2 poderia verificar se o desejo de um pênis maior tem como objetivo ter uma vida sexual mais ativa. Novamente, o Locutor 1 responde que prefere o pênis maior, mostrando que o homem estereotipado em questão é contraditório e foca seu desejo mais em si, no seu físico, do que na utilidade sexual de seu pênis. A crítica, nesse ponto, parte do questionamento dessa virilidade: esse homem deseja um pênis maior para satisfazer seu prazer sexual ou simplesmente por narcisismo? Como o Locutor 1 escolhe " 2 centímetros de pau", deixa claro seu narcisismo acima de seu desejo.

É imprescindível destacarmos a importância de se reconhecer o intertexto. Saber o quanto "vale" uma "suruba com as Panicats" nesse cenário faz com que se meça a escolha do Locutor 1. Ao perceber a intertextualidade, o telespectador compreende que suruba significa sexo grupal, muito desejado pelos homens que querem afirmar sua virilidade, e compreende que as Panicats são assistentes de palco, trabalhando seminuas e exibindo corpos de forma sexualizada em um programa de televisão. A partir disso, o peso da argumentação é dado ao telespectador, o qual pode, inclusive, concordar com todo o padrão estereotipado do vídeo, envolver-se na argumentação do Locutor 2, o que seria, também, uma crítica direta do "Porta dos Fundos" aos homens que se encaixam nessa crítica e estão assistindo ao vídeo.

Em seguida, o Locutor 2 traz outra voz ao texto, questionando se o Locutor 1 prefere “dois centímetros de pau ou passe livre”. Essa nova voz evocada representa questões socioeconômicas e políticas. Ao analisarmos a data de publicação do vídeo, reconhecemos o intertexto referente às mobilizações e aos protestos feitos especialmente em São Paulo pelo "Movimento Passe Livre", o qual lutou por transporte público gratuito e fora da iniciativa privada. Novamente, o Locutor 1 opta por " 2 centímetros de pau", demonstrando que esse desejo é maior do que melhorar uma questão social para todo o país. Devemos nos questionar, aqui, por que o passe livre é escolhido como novo argumento para combater o desejo pelo pênis maior. Essa escolha busca criar o humor por meio de uma referência política e social polêmica, rebaixando-a a uma discussão sobre o pênis. Comparar a possibilidade de ter um pênis maior 
à possibilidade de ter transporte público gratuito a todo país é absurdo, mas cabível no universo do texto em questão e, justamente pelo absurdo, gera o humor.

A próxima pergunta do Locutor 2 ao Locutor 1 é "2 centímetros de pau ou uma viagem com o Luquita da galera?". "Luquita da galera" é uma referência ao ator global Bruno de Luca, taxado de "nerd" e "meio bobão" pelos usuários da internet, segundo o site Yahoo Answers. Porém, esse intertexto só teria seu conteúdo compreendido por uma parcela muito pequena da internet, aquela que está em contato com conteúdos de humor diariamente.

Esse novo argumento busca restringir a piada aos poucos telespectadores que estariam sempre em contato com o canal "Porta dos Fundos". Nesse momento, a escala argumentativa faz sentido somente se o telespectador compreender o quanto seria "valioso", para os humoristas do canal, fazer "uma viagem com o Luquita da galera". Esse argumento ainda seria maior do que uma "suruba com as Panicats" ou do que os argumentos invocados anteriormente para contrapor o desejo pelo pênis maior. Novamente, o Locutor 1 afirma que prefere ter "2 centímetros de pau", demonstrando que, para ele, isso seria mais importante que estar com uma personalidade do humor.

Por conseguinte, o Locutor 2 pergunta ao Locutor 1 se ele prefere " 2 centímetros de pau ou aquela figurinista gostosa do Porta dos Fundos". O primeiro elemento que provoca humor nessa declaração é a metalinguagem. Tratar do "Porta dos Fundos” em um vídeo do "Porta dos Fundos" gera um efeito humorístico bastante significativo, pois é inesperado. Ademais, ao tratar de uma "figurinista gostosa", aqueles que assistem ao canal fazem suas próprias referências, pensando em determinada atriz do canal. Essa nova voz representa questões sexuais envolvendo o ambiente de trabalho (para os atores que se mostram nos personagens nesse momento) ou envolvendo as possibilidades que o próprio telespectador pode evocar, especialmente aquele que assiste com frequência ao canal "Porta dos Fundos" e conhece as atrizes que nele trabalham.

A cada nova voz evocada para contrapor o desejo de um pênis maior, o texto restringe progressivamente os telespectadores que compreenderiam a piada. Isso faz com que aquele que é fã do canal sinta-se especial, "por dentro" do intertexto. Somente aquele que conhece o canal "Porta dos Fundos", o universo do humor, compreende o intertexto e ri com as referências feitas pela constituição polifônica. Mais uma vez, o Locutor 1 mostra sua preferência por "2 centímetros de pau”, mantendo-se na sua escolha quase automaticamente. Essa repetição insistente, sem maior análise, também é geradora do humor, pois se vê a obstinação do Locutor 1 por " 2 centímetros de pau".

Por fim, o Locutor 2 traz uma pergunta inesperada para encerrar o vídeo: "2 centímetros de pau ou 5 centímetros de pau?". A voz inicial, dada pelo desejo de ter um pênis maior, persiste no segundo argumento dado pelo Locutor 2, ou seja, não se alteram as vozes do texto, ambos tratam do desejo de ter mais “centímetros de pau”. O que se altera, nesse caso, é o quanto, em termos de tamanho, o Locutor 1 deseja ter a mais de pênis. Se adotarmos um pensamento lógico, no contexto do diálogo, do humor, do universo machista, imaginaríamos que a resposta do Locutor 1 seria " 5 centímetros de pau”. Porém, ele responde " 2 centrímetros de pau". Nesse momento, o humor pode ser gerado por diversos motivos.

Primeiramente, porque a repetição insistente da resposta do Locutor 1 demonstra sua obsessão cega, sem pensar em qualquer outra possibilidade além dos " 2 centímetros de pau”, uma obsessão tão intensa que é cômica. Em segundo lugar, porque é possível perceber que a questão não é apenas ter um pênis maior, mas ter um tamanho de pênis específico, dado como ideal para o Locutor 1, o que é inesperado para o telespectador, gerando humor. Terceiro, pela quebra inusitada da sequência argumentativa, pois até então outras vozes, outros valores estavam sendo trazidos para a composição do texto e, ao final, isso é quebrado inesperadamente. Por fim, pela resposta inusitada do Locutor 1, pois, já que ele queria um pênis maior, então ele escolheria a opção " 5 centímetros de pau”, mas isso não acontece, justamente pela possibilidade do segundo motivo apresentado anteriormente: a questão não é apenas ter um pênis maior, mas um pênis ideal.

Todas essas questões levam ao humor e, agora, com o argumento final, novamente aquele telespectador que não compreendeu o intertexto dos argumentos anteriores acha graça no texto e é trazido novamente para o universo da piada. A seguir, a escala argumentativa que representa a polifonia do texto pós-créditos: 


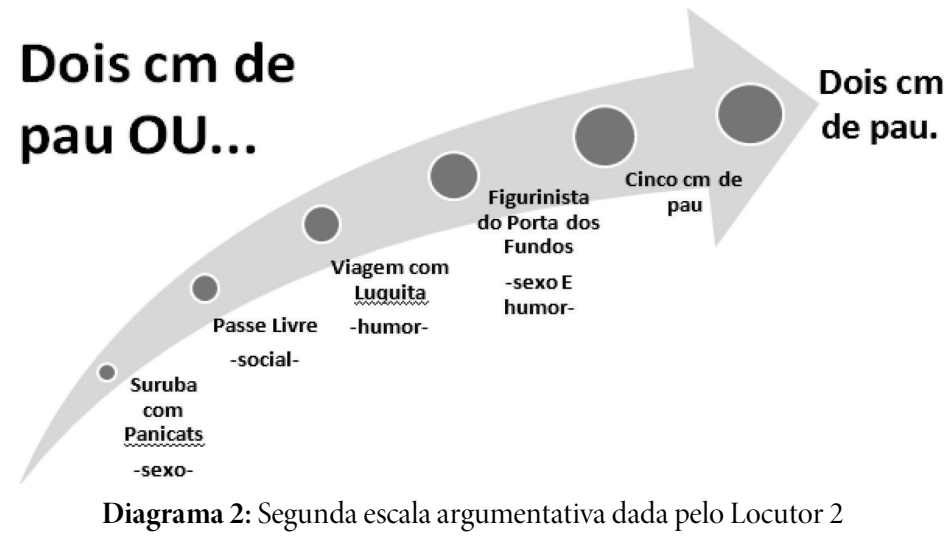

Como é possível observar, a voz da virilidade, expressa pelo desejo de "2 centímetros de pau", é mais forte que as outras apresentadas pelo Locutor 2, uma vez que foi o argumento escolhido pelo Locutor 1 nas alternativas apresentadas.

Essa escala demonstra que, dentro do universo em que o texto se insere, nada é mais importante que ter " 2 centímetros de pau". A composição de vozes, a intertextualidade utilizada e a repetição insistente formam um texto humorístico muito bem delineado e crítico, envolvendo especialmente os fãs do canal.

Para que haja a efetivação da argumentação pretendida, assim como a produção de sentido de humor no interlocutor, comprovando, então, o funcionamento dialógico do discurso, é preciso, portanto, que este interlocutor recupere "[...] os dois enunciatários, o sério e o absurdo, para concretizar o processo de dupla leitura exigido pelo discurso irônico" (PASSETTI, 1995, p. 65), demonstrando a polifonia nas instâncias da produção e da recepção.

\section{CONSIDERAÇÕES FINAIS}

A partir da análise, pudemos chegar a algumas considerações que não pretendem ser únicas, mas válidas o bastante para discutirmos a formação textual heterogênea do texto "É pau, é pedra".

O Locutor 1 é o enunciador representante da insegurança e do desejo de ter "2 centímetros de pau" a mais, e o Locutor 2 é o enunciador representante da segurança viril, do insistente questionador e testador do colega. Vemos dois enunciadores em um jogo argumentativo, em que o Locutor 2 busca dar argumentos cada vez mais convincentes para compreender se o Locutor 1 quer, de fato, ter um pênis com 2 centímetros a mais. Esses estereótipos também funcionam como uma forma de julgamento de valor, uma crítica direta aos tipos retratados no vídeo.

Esse jogo argumentativo só é possível no universo contextual em questão: um encontro de dois homens, em um local informal direcionado a homens, em um momento íntimo, com personagens que, por seu discurso, mostram-se desejosos de uma aparência viril, inquestionável, ligada ao desempenho sexual heteronormativo.

Esse jogo argumentativo só é compreensível no universo do humor. Só se leva em consideração a discussão dos locutores por se tratar de uma piada, esperada justamente pelo leitor/telespectador ao estar acessando um canal de humor.

A partir dessas considerações, podemos analisar alguns pontos específicos sobre a composição textual. Primeiramente, na escala argumentativa dada pelo Locutor 2, o "ou" apresenta outras vozes ao texto, colocando-as em relação de exclusão com a primeira voz (de ter mais " 2 centímetros de pau"). O texto é polifônico porque é necessário que se busquem as outras vozes para compreender o sentido e o humor do texto. Enquanto a primeira voz traz o desejo de virilidade, travestido do desejo de um pênis 2 centímetros 
maior, as vozes introduzidas pelo "ou" trazem outros desejos comuns do atual contexto sócio-histórico, dentre eles o sexo, o dinheiro, o status, o humor, o dever social e a espiritualidade. O entrecruzamento de vozes ocorre em uma construção de exclusão: são questões impossíveis de serem conciliadas, pressupondo um diálogo que prevê preferências.

Em segundo lugar, é indispensável compreendermos por que e para que essas novas vozes foram trazidas ao texto. Elas enfatizam o desejo inicial do Locutor 1, pois, qualquer que fosse a voz trazida para contrapô-lo - inclusive a mesma voz -, não seria suficiente para fazê-lo mudar de ideia. Ademais, demonstram a vontade do Locutor 2 em comprovar a obstinação do Locutor 1 por 2 centímetros a mais de pênis e realizam a crítica maior do vídeo: ao homem "viril", "macho", para o qual nada importa mais que o tamanho ideal do pênis. O tamanho do pênis, nesse caso, representa a obsessão por esse papel viril.

Por fim, todas essas vozes são trazidas ao texto para gerar o humor. É por meio da compreensão delas e das comparações e situações absurdas que o leitor/telespectador compreende e ri da piada, ridicularizando os personagens estereotipados em questão. Tudo isso, com ajuda das expressões, dos elementos audiovisuais e das insistentes repetições, gera o riso, envolve o leitor/telespectador em uma situação cômica.

A intertextualidade também é fator decisivo nessa produção de humor. Por meio dela o leitor/telespectador resgata intertextos e compreende as diversas vozes trazidas ao texto polifônico. A intertextualidade inclui e exclui os leitores/telespectadores, fazendo referências intertextuais específicas, sendo, também, geradora de humor no texto. Na esteira dessa conclusão, salientamos a observação que Bakhtin (1992, p. 140) realiza acerca do processo de enunciação da inscrição do outro no discurso:

[...] a todo instante se encontra nas conversas 'uma citação' ou 'uma referência' àquilo que disse uma determinada pessoa, ao que 'se diz' ou àquilo que 'todos dizem', às palavras de um interlocutor, às nossas próprias palavras anteriormente ditas, a um jornal, a um decreto, a um documento, a um livro.

Por fim, compreendemos que, embora o texto em questão possa ser analisado de maneira mais abrangente (incluindo o excerto inicial do vídeo), uma análise de sua construção heterogênea foi realizada, especialmente no que se refere à sua composição polifônica e intertextual.

\section{REFERÊNCIAS}

BAKHTIN, M. [VOLOCHINOV, Valentin]. Marxismo e filosofia da linguagem. 6. ed. São Paulo: Hucitec, 1992.

BAKHTIN, M. Problemas da poética de Dostoiévski. 3. ed. Tradução de Paulo Bezerra. Rio de Janeiro: Forense Universitária, 2002.

BAKHTIN, M. Estética da criação verbal. Tradução de Paulo Bezerra. São Paulo: Martins Fontes, 2011.

BARROS, D. L. P. de. Dialogismo, polifonia e enunciação. In: BARROS, D. L. P. de; FIORIN, J. L. Dialogismo, polifonia, intertextualidade em torno de Bakhtin. São Paulo: Edusp, 1994.

BARROS, D. L. P. de. Contribuições de Bakhtin às teorias do texto e do discurso. In: FARACO, Carlos Alberto et al. Diálogos com Bakhtin. 2. ed. Curitiba: Editora UFPR, 1999. p. 21-42.

BEZERRA, P. Polifonia. In: BRAIT, Beth (org.). Bakhtin: conceitos-chave. São Paulo: Editora Contexto, 2007.p.191-200.

BRAIT, B. Ironia em perspectiva polifônica. Campinas: Editora da Unicamp, 1996. 
BUTLER, J. Gender trouble: feminism and the subversion of identity. New York: Routledge, 1990.

DUCROT, O. O dizer e o dito. Campinas: Pontes, 1987.

É PAU, É PEDRA. Direção: Ian SBF. Roteiro: Fabio Porchat. São Paulo: Porta dos Fundos, 2013. Disponível em: https://www.youtube.com/watch?v=0r64JMA1tMA.

FÁVERO, L. Paródia e dialogismo. In: BARROS, Diana Luz Pessoa de; FIORIN, José Luiz (org.). Dialogismo, polifonia, intertextualidade. São Paulo: Edusp, 1999.

FIORIN, José Luiz. Polifonia textual e discursiva. In: BARROS, D. L. P. de; FIORIN, J. L. Dialogismo, polifonia, intertextualidade em torno de Bakhtin. São Paulo, SP: Edusp, 1999. p. 29-36.

KOCH, I. G. Villaça. Argumentação e linguagem. São Paulo: Cortez, 2008.

LOPES, E. Discurso literário e dialogismo em Bakhtin. In: BARROS, D. L. P. de; FIORIN, J. L. Dialogismo, polifonia, intertextualidade em torno de Bakhtin. São Paulo: Edusp, 1999. p. 63-81.

PASSETI, M. C. C. O discurso irônico: análise da argumentação irônica em textos opinativos da Folha de S. Paulo. 1998 Dissertação (Mestrado em Letras) - Universidade Estadual Paulista, 1995.

POSSENTI, S. Os humores da língua: análises linguísticas de piadas. Campinas: Mercado de Letras, 1998.

POSSENTI, S. Humor de circunstância. Filologia e Linguística Portuguesa, São Paulo, v. 9, p. 333-344, 2000.

POSSENTI, S. A forma no discurso. In: POSSENTI, Sírio. Discurso, estilo e subjetividade. São Paulo: Martins Fontes, 2001. p. 153182.

PRETI, D. (org.) Análise de textos orais. São Paulo: FFLCH/USP, 1993.

\section{(1) $\circledast$}

Recebido em 13/04/2019. Aceito em 15/06/2019. 